\title{
HAND INJURIES CAUSED BY INJECTION OF CEMENT UNDER PRESSURE
}

\author{
C. H. Hutchinson, Virginia, Orange Free State, South Africa
}

In the gold-mining industry cement is used underground for injection into water-bearing fissures to control the flow of water. The cement, in a thin mud-like solution, is pumped into the fissures under pressures of approximately 3,000 pounds per square inch [210 kilograms per square centimetre]. The handling of a defective rubber hose attached to a cement pump can result in the cement solution's being pumped into the thumb and fingers.

\section{CASE REPORTS}

Case 1-An African aged thirty said that he had been struck by the rubber hose of a cement pump the day before, and complained of a very painful swollen right thumb. Examination revealed no skin injury. The thumb was very swollen and movements were restricted. A fracture was suspected, but radiographs showed linear calcification along the flexor pollicis longus tendon and in the pulp (Fig. 1). This was thought to be an old-standing condition. A radiograph of the opposite thumb did not show any abnormality. The following day the swelling had diminished and the man said that the pain was negligible. He was discharged fit for work. He was readmitted twenty-six days later with an ulcer on the palmar surface of the thumb over the interphalangeal crease. There was discharge of cement granules, serum and pus. He was treated with antibiotics and Eusol dressings, and the swelling gradually subsided. Healing occurred five months from the time of injury. By this time there was limitation of movement at the interphalangeal joint due to an adherent scar.

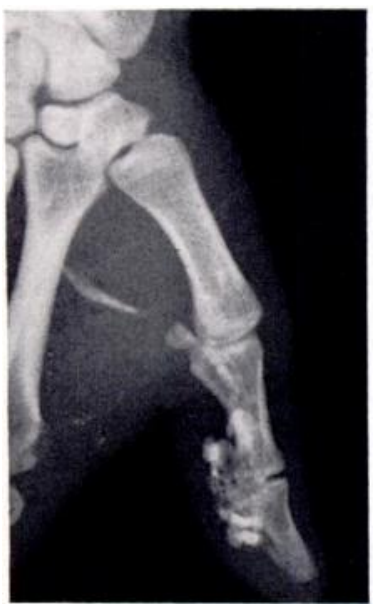

FIG. 1

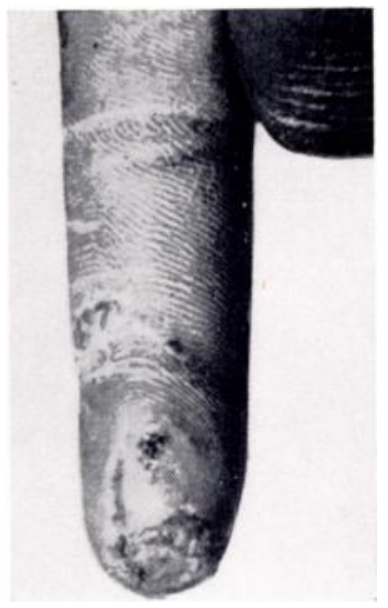

FIG. 2

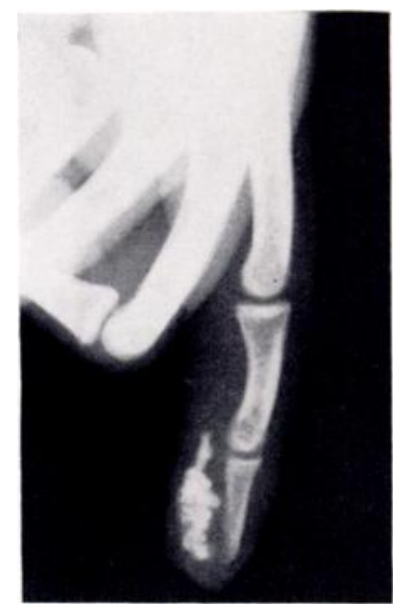

Fig. 3

Case 1. Figure 1-Radiograph showing cement in the long flexor tendon sheath and along the proximal and distal phalanges of the right thumb. Case 2. Figure 2-Right index finger showing ulceration of the pulp. Figure 3-Radiograph showing cement in the pulp of the index finger.

Case 2-An African aged twenty-five said that he had been injured by cement from a rubber hose of a cement pump five weeks before. Examination showed an ulcer of the pulp of the right index finger and a painful swollen finger (Fig. 2) with restricted flexion. There was discharge of cement granules, serum and pus from the ulcerated area. A radiograph of the finger showed radiopaque material in the pulp (Fig. 3). He was treated with antibiotics 
and the finger was amputated at the proximal interphalangeal joint. The stump healed in eight days. Section of the amputated finger showed a small area in the pulp containing gritty material. Histological examination showed granular foreign material lying in the deeper tissues, and a chronic inflammatory reaction in the subcutaneous tissue (Figs. 4 and 5).

After the discovery of these two cases, radiographs were taken of the hands and fingers of fifty-two workers. No further instance of cement injection was discovered at that time.

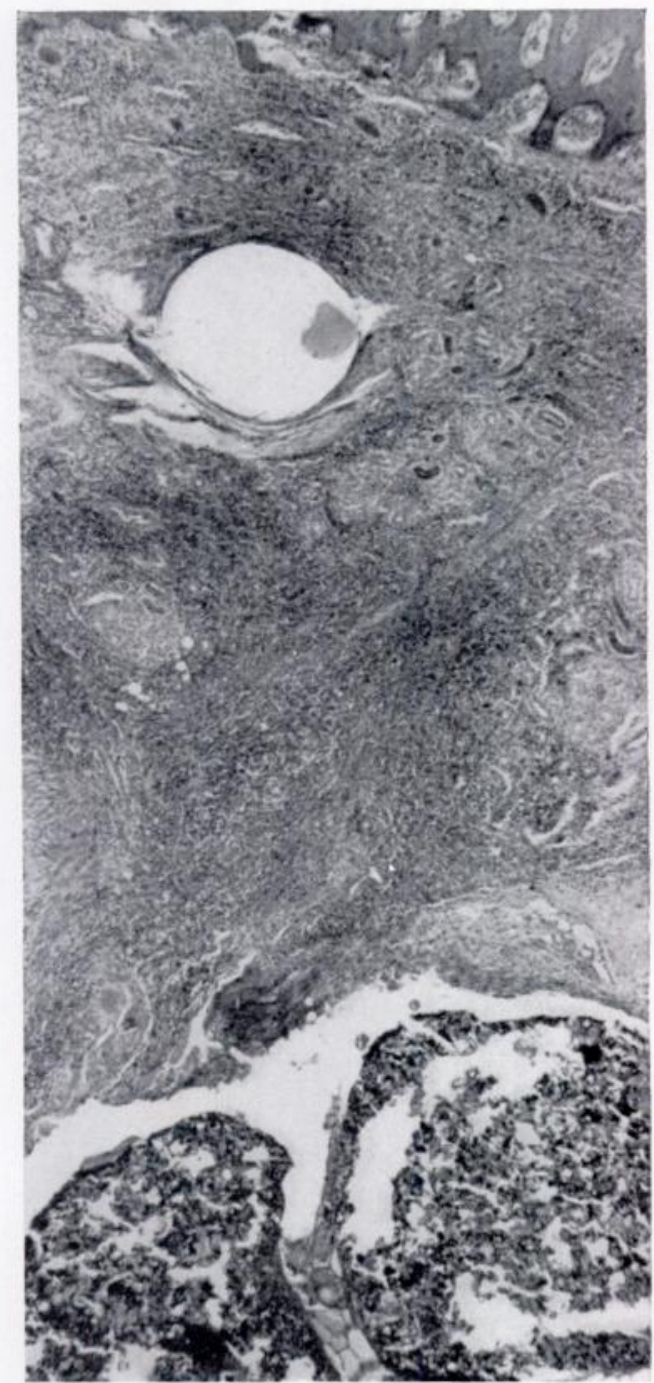

FIG. 4

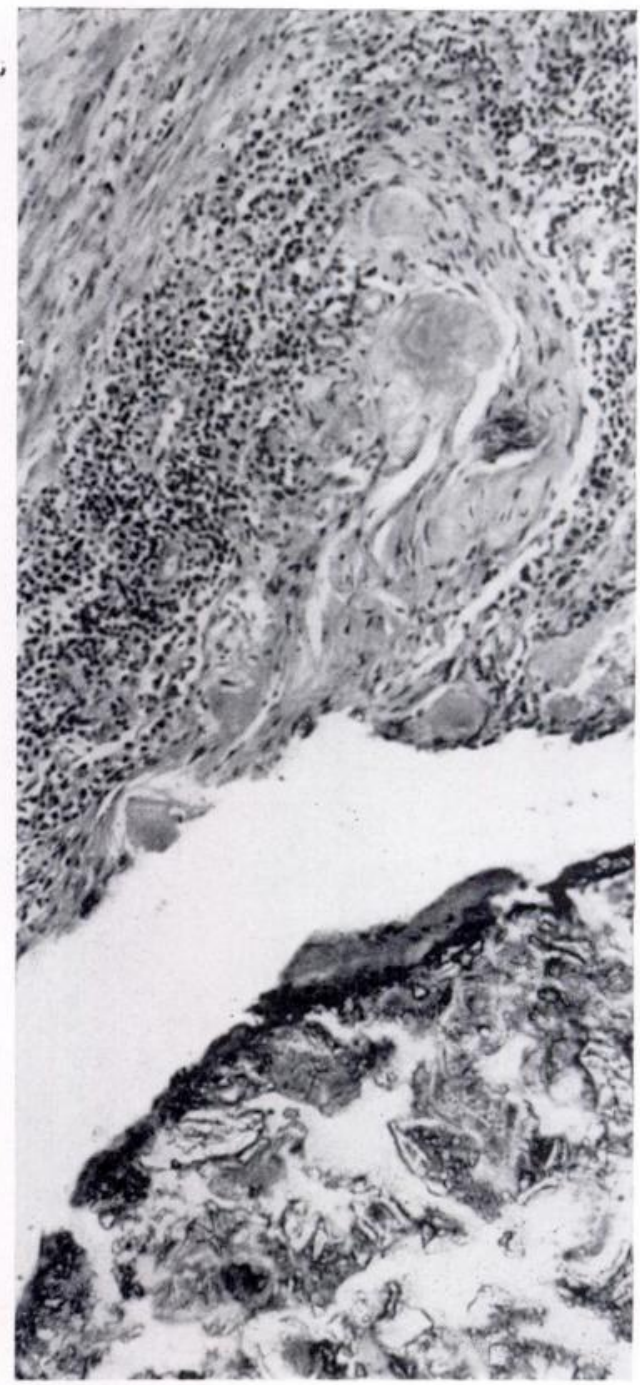

FIG. 5

Case 2-Histological sections, low power $(\times 20)$ (Fig. 4) and high power $(\times 120)$ (Fig. 5), showing aggregates of granular foreign material lying in the deep subcutaneous tissues. A severe chronic inflammatory reaction is present in the surrounding subcutaneous tissue.

Case 3-A cement worker who was injured at work said that while testing a one-inch metal pipe attached to a cement pump he got a small cut on the palmar surface of his right index finger and cement was blown into it. When examined he had a quarter of an inch wound on the palmar surface of his right index finger. There was swelling of the finger and limitation of its movement. Radiographs showed opaque material in the soft tissues and in the flexor sheath (Fig. 6). Under general anaesthesia incisions were made on the palmar surfaces of the finger and as much of the cement as possible was removed. Bacillus coli infection developed, 
and the finger was amputated through the metacarpophalangeal joint five weeks later. He returned to work after a month.

\section{DISCUSSION}

Injection of cement into water-bearing fissures underground has been used in the gold mines since 1936. A search of the medical literature has not revealed any report of hand injuries from the injection of cement under pressure. Many cases of the injection of oil, grease or paint have been reported since 1937. These cases all show similar clinical features and the same pathological reaction. A single case, with radiological changes due to the injection of lead paint, was recorded by Nahigian (1966).

If the hands of cement workers are routinely radiographed when they present with suspicious lesions it is likely that more instances of cement injection will be discovered. With the increased use of high-pressure lubricating guns, airless paint sprays and cement pumps, this type of injury must become more frequent (Lancet 1966).

As the injury is a serious one that may result in deformity or loss of fingers, efforts should be made to prevent its occurrence. The rubber hoses of a cement pump should be inspected regularly for defects before using a cement pump. Since a leak

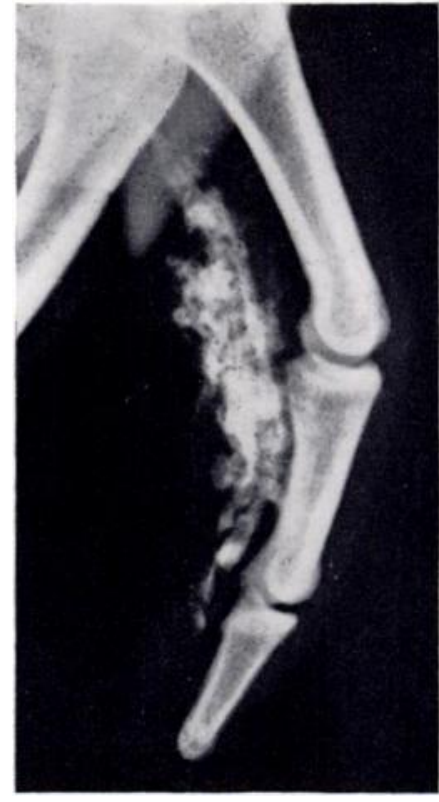

FIG. 6

Case 3-Radiograph showing radiopaque material in the soft tissues in front of the phalanges and also in the flexor sheath.

may escape detestion, cement workers should be provided with thick gloves for protection of the hands and fingers, and should be made aware of the possible dangers of the equipment.

\section{SUMMARY}

1. Three cases of cement injection into the tissues of the thumb and index finger are recorded.

2. This is probably the first description of this type of injection injury.

3. Recommendations are made for the prevention of the injury.

I wish to thank the manager of the Virginia Gold Mining Company for permission to record these cases: also Dr P. Smit; Mr J. C. Allan of the Anatomy Department of the Witwatersrand University for his assistance and encouragement in the discovery of this condition; and $\mathrm{Mr} \mathrm{T}$. Coetzee of the Ernest Oppenheimer Hospital, Welcom, for his advice and help in writing this paper. I am indebted to Mr C. C. Freed, Medical Superintendent of the Cottesloc Hospital, Johannesburg, for permission to quote Case 3 who was treated by $\mathrm{Mr}$. Southgate.

\section{REFERENCES}

ANNOTATION (1966): Injection Accidents in Industry. Lancet, ii, 37.

Nahigian, S. H. (1966): Airless Spray Gun. Journal of the American Medical Association, 195, 688. 